\title{
Effects of Thermal Radiation on Mixed Convection Flow over a Permeable Vertical Shrinking Flat Plate in an Oldroyd-B Fluid
}

(Kesan Sinaran Terma pada Aliran Olakan Campuran terhadap Plat Rata Telap Menegak Mengecut dalam Bendalir Oldroyd-B)

\author{
KOHILAVANI NAGANTHRAN*, ROSLINDA NAZAR \& IOAN POP
}

\begin{abstract}
This study offers the numerical solutions for the problem of mixed convection stagnation-point flow along a permeable vertical flat plate in an Oldroyd-B fluid. The present investigation considers the effects of thermal radiation and heat generation/absorption in the fluid flow. The similarity transformation simplifies the complex model and the bvp $4 c$ function generates the numerical solutions according to the variations in the governing parameters. A higher degree of shrinking hastens flow separations. The dual solutions are visible in the range of buoyancy opposing flow. The results from this study may be useful for the scientist to understand the behaviour of the dilute polymer solutions in the industrial applications, for example, the drag reduction in pipe flows.
\end{abstract}

Keywords: Mixed convection; Oldroyd-B fluid; stability analysis; shrinking plate; stagnation-point flow

\section{ABSTRAK}

Kajian ini memberikan penyelesaian berangka bagi masalah aliran titik genangan olakan campuran sepanjang plat rata telap menegak dalam bendalir Oldroyd-B. Kajian ini mempertimbangkan kesan sinaran terma dan penjanaan/ penyerapan haba dalam aliran bendalir. Penjelmaan keserupaan mempermudahkan model kompleks dan fungsi bvp4c menghasilkan penyelesaian berangka mengikut variasi parameter menakluk. Darjah pengecutan yang lebih tinggi mempercepatkan pemisahan aliran. Penyelesaian dual boleh dilihat dalam julat aliran menentang apungan. Keputusan daripada kajian ini boleh digunakan oleh saintis untuk memahami tingkah laku larutan polimer cair dalam aplikasi perindustrian, contohnya pengurangan seretan dalam aliran paip.

Kata kunci: Aliran titik genangan; analisis kestabilan; bendalir Oldroyd-B; olakan campuran; plat mengecut

\section{INTRODUCTION}

Mixed convection flow collects much respect in passive energy storage systems, for instances the cooling of spent fuel rods in nuclear power applications and modelling of solar collectors and in several heat removal processes (Pop \& Ingham 2001). Acrivos (1958) offered a theoretical work of mixed convection and heat transfer in external flow past a vertical flat plate by using the approximate KarmanPohlhausen method. Chen (1998) is the first person to tackle the problem of mixed convection flow adjacent to vertical stretching sheets. Karwe and Jaluria (1988) explained the influence of buoyancy over a moving plate in casting processing, rolling and extrusion processing, hence discovered that the effect of thermal buoyancy is important when the vertical plate is stretching. The processing of synthetic fibres in the chemical processes, food industries and construction engineering are some of the industrial applications which date the non-Newtonian fluids (Burdujan 2011). Oldroyd-B fluid is engaged under the subclass of rate type non-Newtonian family and is introduced by Oldroyd $(1958,1950)$. There are quite a number of remarkable literature which are dedicated to the development of the theoretical works in an Oldroyd-B fluid such as Fetecau and Fetecau (2003), Fetecau and Kannan (2005), Guillope and Saut (1990), Phan-Thien (1984), Rajagopal and Bhatnagar (1995) and Waters and King (1971). Bhatnagar et al. (1995) commenced the problem of boundary layer flow of an Oldroyd-B fluid towards a permeable stretching sheet in a constant free-stream velocity. Gradually, the scope of mixed convection has been incorporated in the Oldroyd-B fluid by Hayat et al. (2015a, 2014, 2013) and Sajid et al. (2015).

Recently, Hayat et al. (2017) expounded the influence of melting heat and thermal radiation effects in a stretched flow of an Oldroyd-B fluid. Unfortunately, their definition of the mixed convection parameter is not entirely correct because it is not a constant and is a variable of $x$. This motivates the authors to rectify their work by eliminating the effects of the melting heat transfer in the fluid flow. Moreover, we removed the effects of magnetohydrodynamic (MHD) so that the Oldroyd-B fluid behaviour towards the influence of thermal radiation and heat generation/absorption can be observed correctly. We believe that the behaviour of an Oldroyd-B fluid might be misleading if too many effects are included. Additionally, the mixed convection stagnation-point flow 
past a shrinking flat plate in an Oldroyd-B fluid have not been studied before. Therefore, the present work is devoted to investigating the effects of thermal radiation and heat generation/absorption in the mixed convection flow along a vertical permeable shrinking flat plate in an Oldroyd-B fluid. We claim that this work is new and all the presented numerical results are original.

\section{MATHEMATICAL FORMULATION}

We are interested with the steady mixed convection stagnation-point flow of a viscous and incompressible Oldroyd-B fluid along a permeable vertical flat plate, where $x$ and $y$ are the Cartesian coordinates with $x$-axis measured in the vertical direction and the $y$-axis normal to it. The vertical flat plate coincides with the plane $y=0$, and the fluid flows within $y \geq 0$. The plate is stretching/ shrinking vertically with the velocity $u_{w}(x)=b x$, where $b$ $>0$ corresponds to the stretching rate and $b<0$ refers to the shrinking rate. The velocity of the ambient (inviscid) fluid is $u_{e}(x)=a x$, where $a$ is a positive constant. This study uses thermal radiation and heat generation/absorption to inspect the heat transfer in the fluid flow. The surface temperature is $T_{w}(x)$ and the ambient temperature of the fluid is denoted by $T_{\infty}$. It is assumed that the mass velocity is $v_{w}(x)$. The governing boundary layer equations and heat transfer are modelled as follows:

$$
\begin{aligned}
& \frac{\partial u}{\partial x}+\frac{\partial v}{\partial y}=0 \\
& u \frac{\partial u}{\partial x}+v \frac{\partial u}{\partial y}+\lambda_{1}\left(u^{2} \frac{\partial^{2} u}{\partial x^{2}}+2 u v \frac{\partial^{2} u}{\partial x \partial y}+v^{2} \frac{\partial^{2} u}{\partial y^{2}}\right)=u_{e} \frac{d u_{e}}{d x}+ \\
& v \frac{\partial^{2} u}{\partial y^{2}}+v \lambda_{2}\left(u \frac{\partial^{3} u}{\partial x \partial y^{2}}+v \frac{\partial^{3} u}{\partial y^{3}}-\frac{\partial u}{\partial x} \frac{\partial^{2} u}{\partial y^{2}}-\frac{\partial u}{\partial y} \frac{\partial^{2} v}{\partial y^{2}}\right)+g \beta_{T}\left(T-T_{\infty}\right)
\end{aligned}
$$

$$
u \frac{\partial T}{\partial x}+v \frac{\partial T}{\partial y}=\frac{k}{\rho C_{p}} \frac{\partial^{2} T}{\partial y^{2}}+\frac{16 \sigma T_{\infty}^{3}}{3 k^{*} \rho C_{p}} \frac{\partial^{2} T}{\partial y^{2}}+\frac{Q_{0}}{\rho C_{p}}\left(T-T_{\infty}\right)
$$

along with the boundary conditions:

$$
\begin{gathered}
u=u_{w}(x)=b x, v=v_{w}, T=T_{w}(x)=T_{\infty}+T_{0} x \text { at } y=0, \\
u_{e}(x)=a x, T \rightarrow T_{\infty} \text { as } y \rightarrow \infty .
\end{gathered}
$$

where $u, v$ are the velocity components along the $x-$ and $y-$ directions, respectively; $\lambda_{1}$ is the relaxation time; $\lambda_{2}$ is the retardation time; $g$ is the gravitational acceleration; $v$ is the kinematic viscosity; $\beta_{T}$ is the thermal expansion coefficient; $\rho$ denotes fluid density; $k$ is the thermal conductivity; $C_{p}$ is the specific heat; $T$ is the fluid temperature; and $Q_{0}^{p}$ represents heat generation/absorption coefficient. We introduce now the following similarity variables:

$$
\psi=x \sqrt{a v} f(\eta), \quad \theta(\eta)=\left(T-T_{\infty}\right) /\left(T_{w}-T_{\infty}\right), \quad \eta=y \sqrt{a / v}
$$

where $\psi$ is the stream function, which is defined as $u=$ $\partial \psi / \partial y$ and $v=-\partial \psi / \partial x$. Thus, $u$ and $v$ can be written as

$$
u=a x f^{\prime}(\eta), \quad v=-\sqrt{a v} f(\eta)
$$

where primes denote differentiation with respect to $\eta$. The substitution of variables (5) and (6) into yield the following ordinary (similarity) equations while the continuity equation is hold identical:

$$
\begin{aligned}
& f^{\prime \prime \prime}-f^{\prime 2}+f f^{\prime \prime}+1+\beta_{1}\left(2 f f^{\prime} f^{\prime \prime}-f^{2} f^{\prime \prime \prime}\right)+ \\
& \beta_{2}\left(f^{\prime \prime 2}-f f^{i v}\right)+\lambda \theta=0 \\
& \frac{1}{\operatorname{Pr}}\left(1+\frac{4}{3} N r\right) \theta^{\prime \prime}+f \theta^{\prime}-f^{\prime} \theta+\xi \theta=0
\end{aligned}
$$

along with the boundary conditions

$$
\begin{gathered}
f(0)=s, \quad f^{\prime}(0)=\alpha, \quad \theta(0)=1 \\
f^{\prime}(\eta) \rightarrow 1, \quad f^{\prime \prime}(\eta) \rightarrow 0, \quad \theta(\eta) \rightarrow 0 \quad \text { as } \quad \eta \rightarrow \infty
\end{gathered}
$$

where $\beta_{1}$ and $\beta_{2}$ are the dimensionless relaxation and retardation time constants, respectively, $\lambda$ is the constant mixed convection parameter; $\mathrm{Pr}$ is the Prandtl number; $\mathrm{Nr}$ is the radiation parameter; $\xi$ is the heat generation/ absorption parameter; $s$ denotes mass flux parameter; and $\alpha$ is the stretching/shrinking parameter, which are defined as

$$
\begin{aligned}
& \operatorname{Pr}=v \rho C_{p} / k, \beta_{1}=\lambda_{1} a, \beta_{2}=\lambda_{2} a, \lambda=G r_{x} / \operatorname{Re}_{x}^{2} \\
& \alpha=b / a, s=-v_{w} / \sqrt{a v}, \xi=Q_{0} / a \rho C_{p}, N r=4 \sigma T_{\infty}^{3} / k k *
\end{aligned}
$$

with $G r_{x}=g \beta_{T}\left(T_{w}-T_{\infty}\right) x^{3} / v^{2}$ being the local Grashof number and $\operatorname{Re}_{x}=u_{e}(x) x / v$ is the local Reynolds number. It should be noticed that $\lambda>0$ and $\lambda<0$ correspond to assisting flow and opposing flow, respectively, $\alpha>0$ symbolizes the stretching vertical flat plate while $\alpha<0$ indicates a shrinking vertical flat plate, $s<0$ signifies suction while $s<0$ implies injection and $\xi>0$ denotes heat source whereas $\xi<0$ specifies heat sink. The physical quantities of interest are the skin friction coefficient $C_{f}$ and the local Nusselt number $N u_{x}$, which are given by

$$
C_{f}=\tau_{w} / \rho u_{e}^{2}, \quad N u_{x}=x q_{w} / k\left(T_{w}-T_{\infty}\right)
$$

where $\tau_{w}$ is the skin friction along the surface of the stretching/shrinking plate; and $q_{w}$ is the heat flux from the surface of the plate, which are defined as (Hayat et al. 2015a, 2015b). 


$$
\begin{aligned}
& \tau_{w}=\frac{\mu}{1+\beta_{1}}\left[\frac{\partial u}{\partial y}+\lambda_{2}\left(u \frac{\partial^{2} u}{\partial x \partial y}+u \frac{\partial^{2} v}{\partial x^{2}}+v \frac{\partial^{2} u}{\partial y^{2}}\right)\right]_{y=0}, \\
& q_{w}=-\left(k+\frac{16 \sigma T_{\infty}^{3}}{3 k^{*}}\right)\left(\frac{\partial T}{\partial y}\right)_{y=0}
\end{aligned}
$$

Substituting (5) into (12) and using (11), the reduced skin friction coefficient and the reduced local Nusselt number can be attained as follows:

$$
\begin{aligned}
& \operatorname{Re}_{x}^{1 / 2} C_{f}=\frac{1}{1+\beta_{1}}\left\{f^{\prime \prime}(0)+\beta_{2}\left[f^{\prime}(0) f^{\prime \prime}(0)-f(0) f^{\prime \prime \prime}(0)\right]\right\} \\
& \operatorname{Re}_{x}^{-1 / 2} N u_{x}=-\left(1+\frac{4}{3} N r\right) \theta^{\prime}(0)
\end{aligned}
$$

\section{STABILITY ANALYSIS}

By pursuing the pioneered work by Merkin (1985) and Roşca and Pop (2013), the unsteady form of this problem can be presented as follows:

$$
\begin{aligned}
& \frac{\partial u}{\partial t}+u \frac{\partial u}{\partial x}+v \frac{\partial u}{\partial y}+\lambda_{1}\left(u^{2} \frac{\partial^{2} u}{\partial x^{2}}+2 u v \frac{\partial^{2} u}{\partial x \partial y}+v^{2} \frac{\partial^{2} u}{\partial y^{2}}\right)= \\
& u_{e} \frac{d u_{e}}{d x}+v \frac{\partial^{2} u}{\partial y^{2}}+v \lambda_{2}\left(u \frac{\partial^{3} u}{\partial x \partial y^{2}}+v \frac{\partial^{3} u}{\partial y^{3}}-\frac{\partial u}{\partial x} \frac{\partial^{2} u}{\partial y^{2}}-\frac{\partial u}{\partial y} \frac{\partial^{2} v}{\partial y^{2}}\right)+ \\
& g \beta_{T}\left(T-T_{\infty}\right)
\end{aligned}
$$

$$
\frac{\partial T}{\partial t}+u \frac{\partial T}{\partial x}+v \frac{\partial T}{\partial y}=\frac{k}{\rho C_{p}} \frac{\partial^{2} T}{\partial y^{2}}+\frac{16 \sigma T_{\infty}^{3}}{3 k^{*} \rho C_{p}} \frac{\partial^{2} T}{\partial y^{2}}+\frac{Q_{0}}{\rho C_{p}}\left(T-T_{\infty}\right)
$$

where $t$ denotes dimensionless time. The new similarity transformations are

$$
\begin{aligned}
& u=a x \partial f / \partial \eta(\eta, \tau), v=-\sqrt{a v} f(\eta, \tau), \\
& \theta(\eta, \tau)=\left(T-T_{\infty}\right) /\left(T_{w}-T_{\infty}\right), \eta=y \sqrt{a / v}, \tau=a t
\end{aligned}
$$

The substitution of (16) into (14) and (15) will yield the following system of equations:

$$
\begin{aligned}
& \frac{\partial^{3} f}{\partial \eta^{3}}-\left(\frac{\partial f}{\partial \eta}\right)^{2}+f \frac{\partial^{2} f}{\partial \eta^{2}}+1+\beta_{1}\left[2 f \frac{\partial f}{\partial \eta} \frac{\partial^{2} f}{\partial \eta^{2}}-(f)^{2} \frac{\partial^{3} f}{\partial \eta^{3}}\right]+ \\
& \beta_{2}\left[\left(\frac{\partial^{2} f}{\partial \eta^{2}}\right)^{2}-f \frac{\partial^{4} f}{\partial \eta^{4}}\right]+\lambda \theta-\frac{\partial^{2} f}{\partial \eta \partial \tau}=0 \\
& \frac{1}{\operatorname{Pr}}\left(1+\frac{4}{3} N r\right) \frac{\partial^{2} \theta}{\partial \eta^{2}}-\frac{\partial f}{\partial \eta} \theta+f \frac{\partial \theta}{\partial \eta}+\theta \xi-\frac{\partial \theta}{\partial \tau}=0
\end{aligned}
$$

$$
\begin{gathered}
f(0, \tau)=s, \quad \frac{\partial f}{\partial \eta}(0, \tau)=\alpha, \quad \theta(0, \tau)=1 \\
\frac{\partial f}{\partial \eta}(\eta, \tau) \rightarrow 1, \quad \frac{\partial^{2} f}{\partial \eta^{2}}(\eta, \tau) \rightarrow 0, \quad \theta(\eta, \tau) \rightarrow 0 \quad \text { as } \quad \eta \rightarrow \infty
\end{gathered}
$$

We assume the solutions of (17) - (19) are given in (20), where $f=f_{0}$ and $\theta=\theta_{0}$ are the base solutions which are obtained in the previous section, and are then perturbed with the disturbance so that the behaviour of the stability can be determined (Weidman et al. 2006).

$$
f(\eta, \tau)=f_{0}(\eta)+e^{-\gamma \tau} F(\eta, \tau), \theta(\eta, \tau)=\theta_{0}(\eta)+e^{-\gamma \tau} H(\eta, \tau)
$$

where $\gamma$ is an unknown eigenvalue parameter, and also $F(\eta, \tau)$ and $H(\eta, \tau)$ are relatively small contrasted with the steady state solutions $f_{0}(\eta)$ and $\theta_{0}(\eta)$. Substitution of (20) into (17) - (19) will give the following system of equations:

$$
\begin{aligned}
& \frac{\partial^{3} F}{\partial \eta^{3}}+f_{0} \frac{\partial^{2} F}{\partial \eta^{2}}-2 \frac{\partial f_{0}}{\partial \eta} \frac{\partial F}{\partial \eta}+\frac{\partial^{2} f_{0}}{\partial \eta^{2}} F+2 \beta_{1} f_{0} \frac{\partial^{2} f_{0}}{\partial \eta^{2}} \frac{\partial F}{\partial \eta}+ \\
& 2 \beta_{1} \frac{\partial f_{0}}{\partial \eta} \frac{\partial^{2} f_{0}}{\partial \eta^{2}} F+2 \beta_{1} f_{0} \frac{\partial f_{0}}{\partial \eta} \frac{\partial^{2} F}{\partial \eta^{2}}-2 \beta_{1} f_{0} \frac{\partial^{3} f_{0}}{\partial \eta^{3}} F- \\
& \beta_{1}\left(f_{0}\right)^{2} \frac{\partial^{3} F}{\partial \eta^{3}}+2 \beta_{2} \frac{\partial^{2} f_{0}}{\partial \eta^{2}} \frac{\partial^{2} F}{\partial \eta^{2}}-\beta_{2} f_{0} \frac{\partial^{4} F}{\partial \eta^{4}}-\beta_{2} \frac{\partial^{4} f_{0}}{\partial \eta^{4}} F+ \\
& \lambda H+\gamma \frac{\partial F}{\partial \eta}-\frac{\partial^{2} F}{\partial \eta \partial \tau}=0 \\
& \frac{1}{\operatorname{Pr}}\left(1+\frac{4}{3} N r\right) \frac{\partial^{2} H}{\partial \eta^{2}}+f_{0} \frac{\partial H}{\partial \eta}-\frac{\partial f_{0}}{\partial \eta} H+ \\
& F \frac{\partial \theta_{0}}{\partial \eta}-\frac{\partial F}{\partial \eta} \theta_{0}+\xi H+\gamma H-\frac{\partial H}{\partial \tau}=0
\end{aligned}
$$

subject to the boundary conditions

$$
\begin{gathered}
F(0, \tau)=0, \quad \frac{\partial F}{\partial \eta}(0, \tau)=0, \quad H(0, \tau)=0 \\
\frac{\partial F}{\partial \eta}(\eta, \tau) \rightarrow 0, \quad \frac{\partial^{2} F}{\partial \eta^{2}}(\eta, \tau)=0 \quad H(\eta, \tau) \rightarrow 0 \quad \text { as } \quad \eta \rightarrow \infty
\end{gathered}
$$

As has been recommended by Weidman et al. (2006), we check the stability of the steady-state flow and heat transfer solutions namely $f_{0}(\eta)$ and $\theta_{0}(\eta)$ by fixing $\tau \rightarrow 0$ and hence $F=F_{0}(\eta)$ and $H=H_{0}(\eta)$ in (21) - (23). Thus, we have to solve the following linearized eigenvalue problem:

$$
\begin{aligned}
& F_{0}^{\prime \prime \prime}+f_{0} F_{0}^{\prime \prime}-2 f_{0}^{\prime} F_{0}^{\prime}+f_{0}^{\prime \prime} F_{0}+2 \beta_{1} f_{0} f_{0}^{\prime \prime} F_{0}^{\prime}+2 \beta_{1} F_{0} f_{0}^{\prime} f_{0}^{\prime \prime}+ \\
& 2 \beta_{1} f_{0} f_{0}^{\prime} F_{0}^{\prime \prime}-2 \beta_{1} f_{0} f_{0}^{\prime \prime \prime} F_{0}-\beta_{1}\left(f_{0}\right)^{2} F_{0}^{\prime \prime \prime}+2 \beta_{2} f_{0}^{\prime \prime} F_{0}^{\prime \prime}- \\
& \beta_{2} f_{0} F_{0}^{i v}-\beta_{2} f_{0}^{i v} F_{0}+\lambda H_{0}+\gamma F_{0}^{\prime}=0
\end{aligned}
$$

along with the boundary conditions 


$$
\begin{aligned}
& \frac{1}{\operatorname{Pr}}\left(1+\frac{4}{3} N r\right) H_{0}^{\prime \prime}+f_{0} H_{0}^{\prime}-f_{0}^{\prime} H_{0}+ \\
& F_{0} \theta_{0}^{\prime}-F_{0}^{\prime} \theta_{0}+\xi H_{0}+\gamma H_{0}=0
\end{aligned}
$$

with the boundary conditions

$$
\begin{gathered}
F_{0}(0)=0, \quad F_{0}^{\prime}(0)=0, \quad H_{0}(0)=0 \\
F_{0}^{\prime}(\eta) \rightarrow 0, \quad F_{0}^{\prime \prime}(\eta) \rightarrow 0, H_{0}(\eta) \rightarrow 0 \quad \text { as } \quad \eta \rightarrow \infty
\end{gathered}
$$

The boundary condition $F_{0}^{\prime \prime}(\eta) \rightarrow 0$ can be replaced by a normalizing boundary condition, such that $F_{0}^{\prime \prime \prime}(0)=1$ (Harris et al. 2009). The smallest eigenvalue $\left(\gamma_{1}\right)$ will prove the stability of the steady-state flow solution by setting some fixed values for $\beta_{1}, \beta_{2}, \lambda, \operatorname{Pr}, N r, \xi$, s and $\alpha$.

\section{RESULTS AND DISCUSSION}

The MATLAB solver bvp4c function solves the system of nonlinear ordinary differential equations (7) and (8) subject to the boundary conditions (9) numerically. All velocity and temperature profiles do meet the far field boundary conditions (9) asymptotically. The present work can generate dual solutions by employing different initial guess values. Table 1 reports the comparison values of $f^{\prime \prime}(0)$ with the previous literature when $\beta_{1}=\beta_{2}=0$ (viscous fluid). It shows a good agreement and proves that bvp4c solver is an effective numerical approach to solve the boundary value problems. Figure 1(a) illustrates the increment trend of $\operatorname{Re}_{x}^{1 / 2} C_{f}$ as $s$ increases. The effect of suction facilitates the fluid to penetrate the flat plate. However, the shrinking flat plate reduces the area exposed to the fluid flow and limits the availability of the suction gaps. This will initiate the wall shear stress to increase. Figure 1(b) confirms the situation as the momentum boundary layer thickness decreases as the strength of $s$ increases. Figure 1(a) also highlights the higher values of $\operatorname{Re}_{x}^{1 / 2} C_{f}$ in the range of assisting flow than the values of $\operatorname{Re}_{x}^{1 / 2} C_{f}$ in the region of opposing flow. In the assisting flow, the buoyant force helps to maintain the fluid flow along the shrinking permeable flat plate by reducing the momentum boundary layer thickness. Eventually, the velocity gradient increases and so the value of $\operatorname{Re}_{x}^{1 / 2} C_{f}$ is

TABLE 1 . Comparison of results for $f^{\prime \prime}(0)$ when $\beta_{1}=\beta_{2}=\lambda=s=0$

\begin{tabular}{ccccccc}
\hline & \multicolumn{2}{c}{ Present results } & \multicolumn{2}{c}{ Bhattacharyya and Layek (2011) } & \multicolumn{2}{c}{ Wang (2008) } \\
\cline { 2 - 7 }$\alpha$ & First solution & $\begin{array}{c}\text { Second } \\
\text { solution }\end{array}$ & $\begin{array}{c}\text { First } \\
\text { solution }\end{array}$ & $\begin{array}{c}\text { Second } \\
\text { solution }\end{array}$ & First solution & $\begin{array}{c}\text { Second } \\
\text { solution }\end{array}$ \\
\hline-0.25 & 1.402241 & - & 1.40224051 & - & 1.40224 & - \\
-0.50 & 1.495670 & - & 1.49566972 & - & 1.49567 & - \\
-0.625 & 1.507156 & - & 1.50715673 & - & - & - \\
-0.75 & 1.489298 & - & 1.4892811 & - & 1.48930 & - \\
-1.00 & 1.328817 & 0 & 1.32881689 & 0 & 1.32882 & 0 \\
-1.15 & 1.082231 & 0.116702 & 1.08223164 & 0.11670230 & 1.08223 & 0.116702 \\
-1.20 & 0.932474 & 0.233650 & 0.93247277 & 0.23364910 & - & - \\
-1.22 & 0.845110 & 0.308849 & - & - & - & - \\
-1.2465 & 0.584282 & 0.554296 & 0.58429146 & 0.55428565 & 0.55430 & - \\
\hline
\end{tabular}

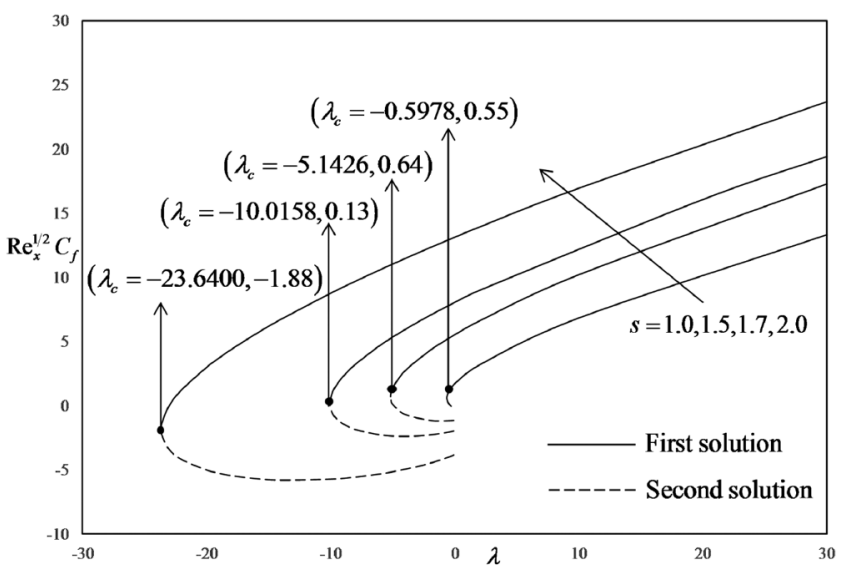

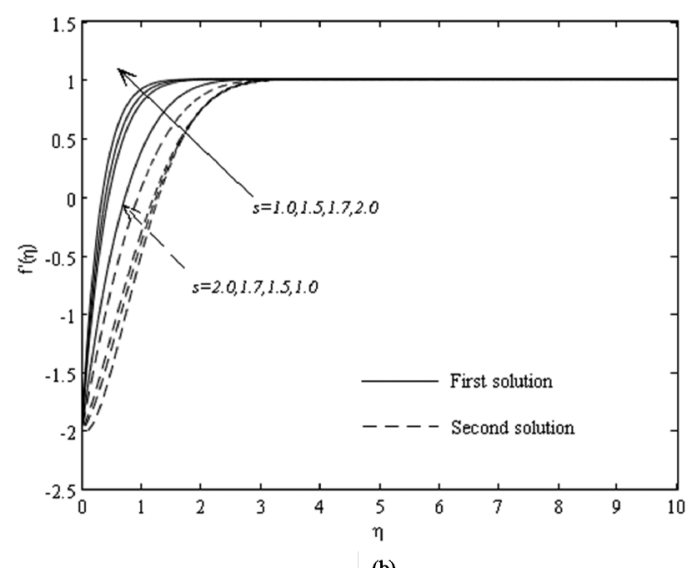

FIGURE 1. (a) Variations of $\operatorname{Re}_{x}^{1 / 2} C_{f}$ with $s$, (b) Velocity profiles, $f^{\prime}(\eta)$ at $\lambda=-0.5$ when $\beta_{1}=0.6, \beta_{2}=0.4, N r=0.5, \operatorname{Pr}=2.59, \xi=0.5$ and $\alpha=-2$ 
higher than the value of $\mathrm{Re}_{x}^{1 / 2} C_{f}$ in the buoyancy opposed flow. We attest that sufficient suction is necessary to delay the flow separation and matches with the findings by Miklavčič and Wang (2006).

Figure 2(a) notifies that $\operatorname{Re}_{x}^{-1 / 2} N u_{x}$ increases as $s$ increases. The act of suction which allows the fluid molecules to fill the shrinking vertical flat plate triggers the heat flux from the surface of the plate to increase. Thus, the thinner thermal boundary layer thickness affects the temperature gradient to be steeper as $s$ increases and hence supports the heat transfer enhancement. This can be perceived from Figure 2(b). We noticed that the value of $\operatorname{Re}_{x}^{-1 / 2} N u_{x}$ appears to be higher in the assisting flow compared to the value of $\mathrm{Re}_{x}^{-1 / 2} N u_{x}$ in the opposing flow. This happened because the effect of the free convection dominates the heat transfer process when $\lambda>0$. The higher heat flux at the surface of the flat plate, the assistances of the buoyant force and the heat source from the fluid flow improve the heat transfer. The opposite behaviour can be identified for the opposing flow $(\lambda<0)$ where the force convection is significant to transfer the heat energy. Figure 3(a) and 3(b) discuss the effects of the stretching/ shrinking parameter $(\alpha)$ with respect to $\operatorname{Re}_{x}^{1 / 2} C_{f}$ and $\operatorname{Re}_{x}^{-1 / 2}$ $N u_{x}$. Figure 3(a) illustrates the increment of $\operatorname{Re}_{x}^{1 / 2} C_{f}$ as the vertical flat plate is shrinking. Although the shrinking flat plate forms the opposing flow in the boundary layer, yet the buoyant force sustains the boundary layer from being separated from the surface of the plate. Figure 3(b) typifies the increment trend of $\mathrm{Re}_{x}^{-1 / 2} N u_{x}$ as $\alpha$ ranges from negative to positive values. The permeable stretching flat plate enlarges the suction gaps which attracts more molecules to fill the flat plate. Consequently, the heat flux from the surface of the plate rises and reduces the temperature boundary layer thickness, which directly increases the rate of heat transfer. Figure 4(a) and 4(b) depicts the decrease in $\operatorname{Re}_{x}^{1 / 2} C_{f}$ and $\mathrm{Re}_{x}^{-1 / 2} N u_{x}$ when the radiation parameter $(\mathrm{Nr})$ increases within the range of the opposing flow $(\lambda<0)$. As the influence of $\mathrm{Nr}$ becomes stronger, the velocity and temperature boundary layer thickness increases and further decreases the values of

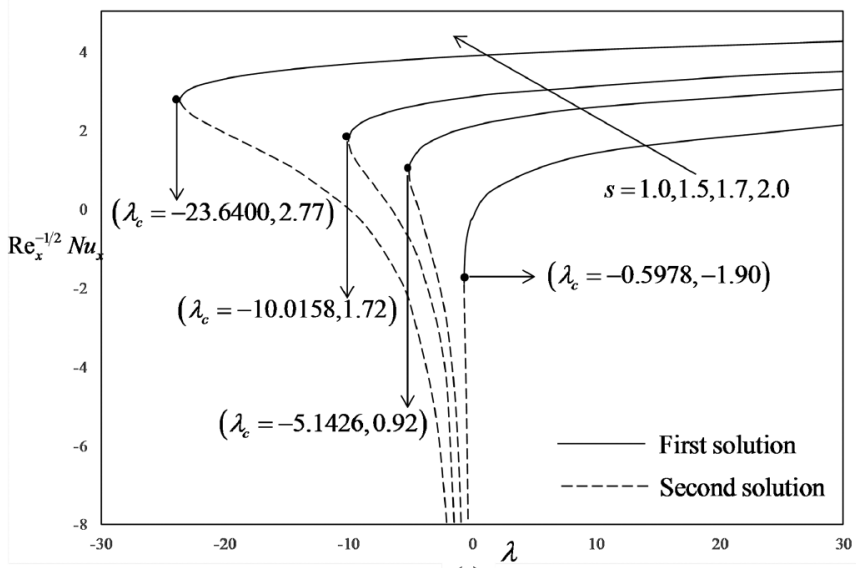

(a)

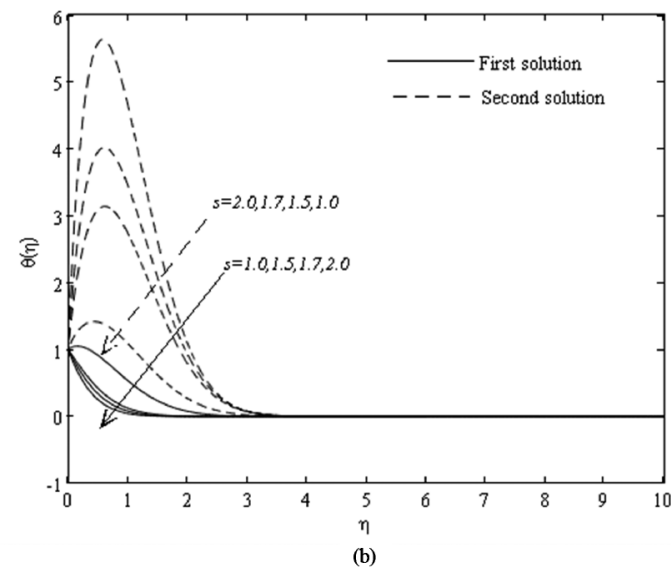

(b)

FIGURE 2. (a) Variations of $\operatorname{Re}_{x}^{1 / 2} N u$ with $s$, (b) Temperature profiles, $\theta(\eta)$ at $\lambda=-0.5$ when $\beta_{1}=0.6, \beta_{2}=0.4, N r=0.5, \operatorname{Pr}=2.59, \xi=0.5$ and $\alpha=-2$
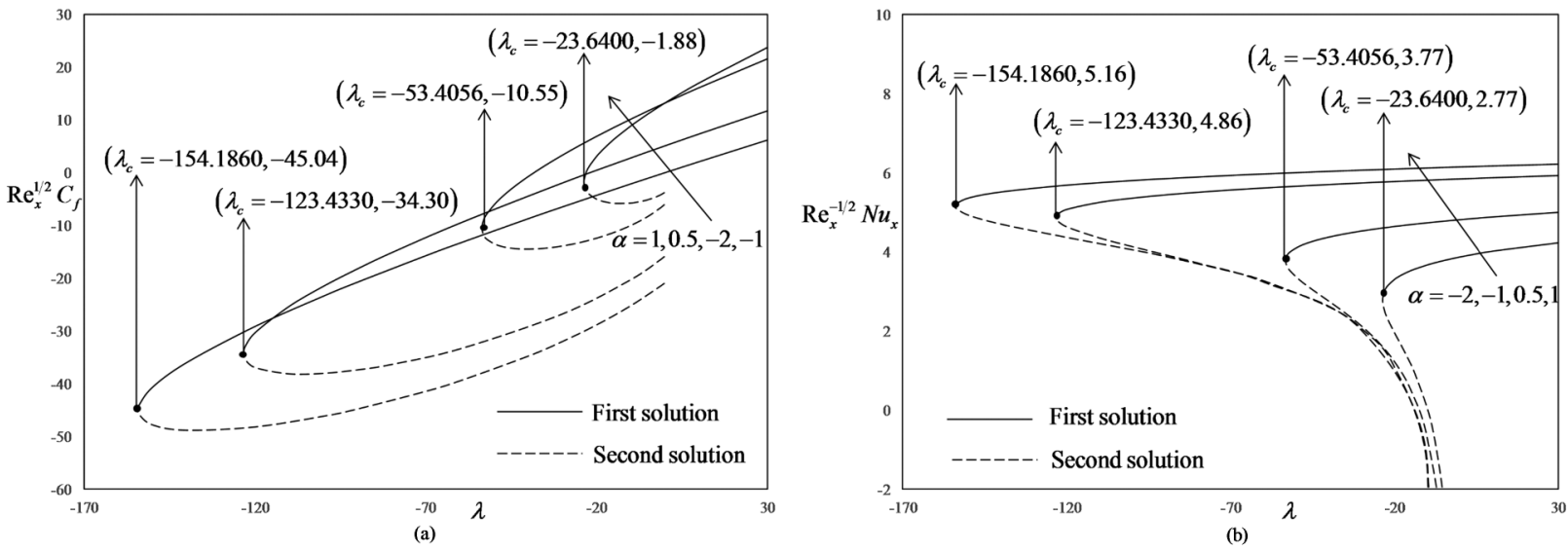

FIGURE 3. (a) Variations of $\operatorname{Re}_{x}^{1 / 2} C_{f}$, (b) Variations of $\operatorname{Re}_{x}^{-1 / 2} N u$ with $\alpha$ when $\beta_{1}=0.6, \beta_{2}=0.4, N r=0.5, \operatorname{Pr}=2.59, \xi=0.5$ and $s=2$ 


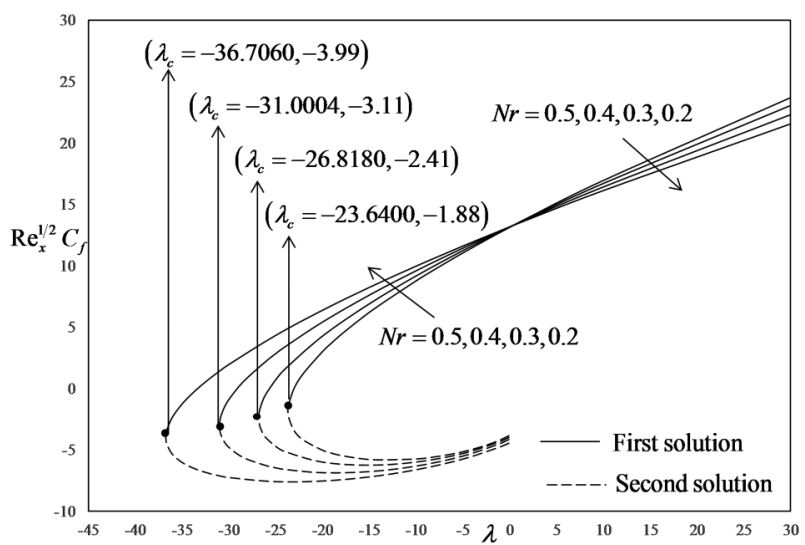

(a)

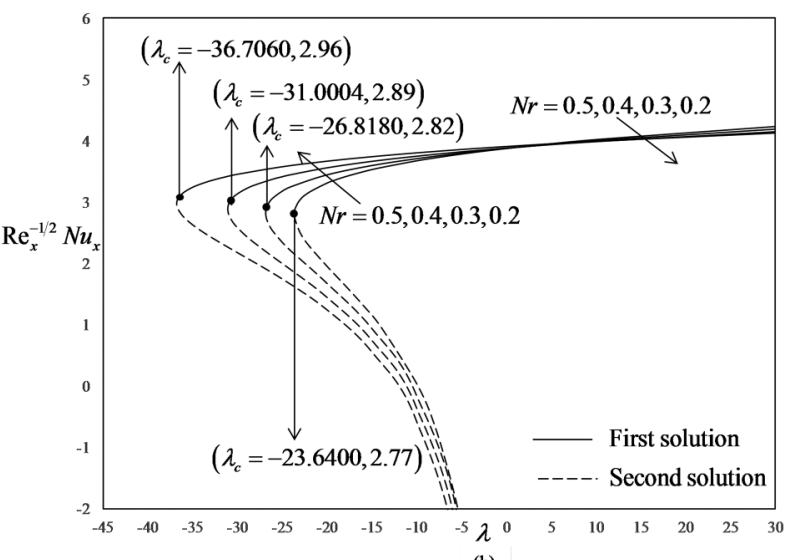

(b)

FIGURE 4. (a) Variations of $\operatorname{Re}_{x}^{1 / 2} C_{f}$, (b) Variations of $\mathrm{Re}_{x}^{-1 / 2} N u$ with $N r$ when $\alpha=-2 . \beta_{1}=0.6, \beta_{2}=0.4, \operatorname{Pr}=2.59, \xi=0.5$ and $s=2$

$\mathrm{Re}_{x}^{1 / 2} C_{f}$ and $\mathrm{Re}_{x}^{-1 / 2} N u_{x}$, respectively. Figure 5(a) spectacles the decrement of $\operatorname{Re}_{x}^{1 / 2} C_{f}$ as the heat generation/absorption parameter $(\xi)$ ranges from negative to positive values, in the opposing flow. Conversely, $\operatorname{Re}_{x}^{1 / 2} C_{f}$ behaves differently within the range of assisting flow, where $\mathrm{Re}_{x}^{1 / 2} C_{f}$ increases as $\xi$ increases. This may be because of the buoyant force

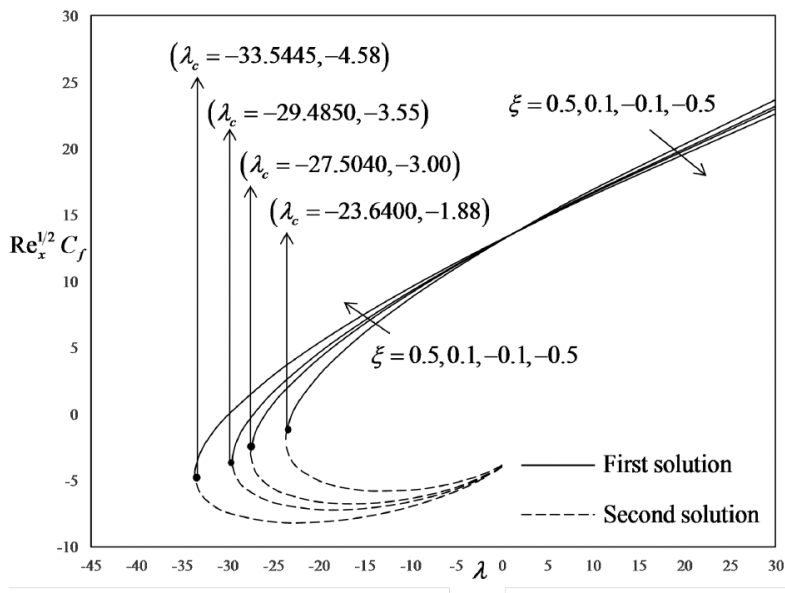

(a)

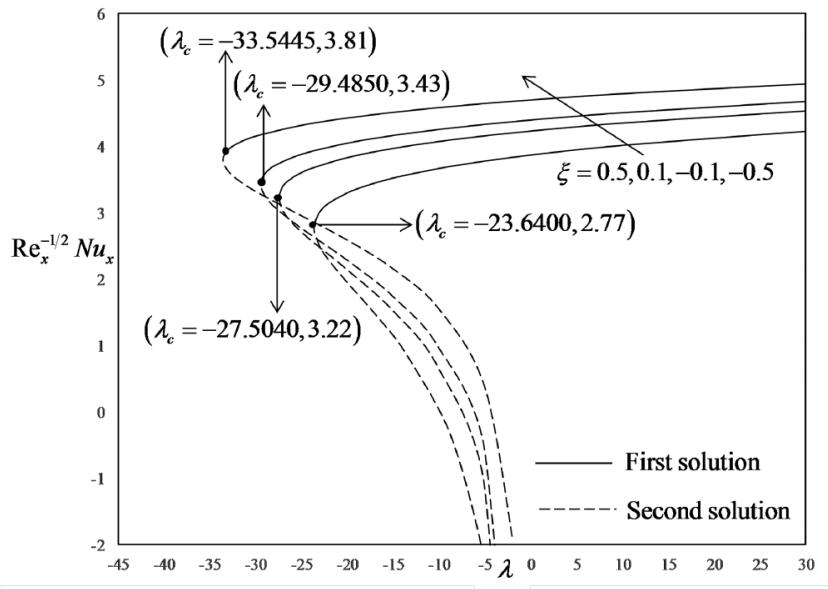

(b)

FIGURE 5. (a) Variations of $\mathrm{Re}_{x}^{1 / 2} C_{f}$, (b) Variations of $\operatorname{Re}_{x}^{-1 / 2} N u$ with $\xi$ when $\alpha=-2 . \beta_{1}=0.6, \beta_{2}=0.4, \operatorname{Pr}=2.59, \mathrm{Nr}=0.5$ and $s=2$

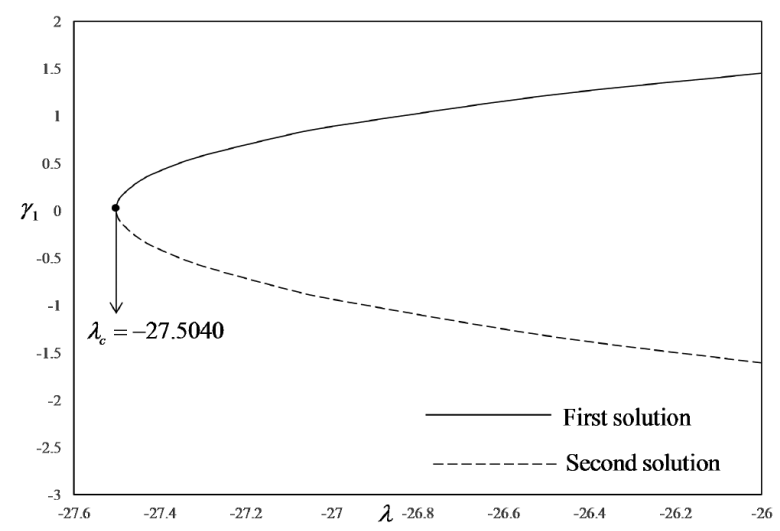

FIGURE 6. Smallest eigenvalues, $\gamma_{1}$ when $\beta_{1}=0.6, \beta_{2}=0.4$, $N r=0.5, \operatorname{Pr}=2.59, \xi=0.1, s=2$ and $\alpha=-2$ 
that maintains the flow from separated from the surface of the plate. Figure 5(b) elucidates the increment in $\mathrm{Re}_{x}^{-1 / 2}$ $N u_{x}$ as $\xi$ ranges from positive to negative. As the heat sinks in the fluid flow, the temperature gradient increases at the surface of the flat plate and so improves the rate of heat transfer. Figure 6 discovers the stability of the dual solutions. The first solution is a stable solution because it yields positive smallest eigenvalues. The positive smallest eigenvalues representing the stabilizing property of the first solution and makes it controls the given disturbance. On the other hand, the second solution is an unstable solution as its smallest eigenvalue ranges within the negative values. The negative smallest eigenvalues connote the growth of the disturbance of the second solution which suggests it to be unstable and may have other logical interpretation. The $\lambda_{c}=-27.5040$ stands as the turning point that spots the transition sign of the smallest eigenvalues from positive (stable) to negative (unstable).

\section{CONCLUSION}

This paper accentuates on the effects of thermal radiation and heat generation/absorption on the mixed convection stagnation-point flow adjacent to a permeable vertical shrinking flat plate in an Oldroyd-B fluid. The increment in $s$ increases $\operatorname{Re}_{x}^{1 / 2} C_{f}$ and $\mathrm{Re}_{x}^{-1 / 2} N u_{x}$. The diminution in $N r$ and $\xi$ lessen the values of $\operatorname{Re}_{x}^{1 / 2} C_{f}$ and $\operatorname{Re}_{x}^{-1 / 2} N u_{x}$. Meanwhile, the increment in $\alpha$ decreases but increases $\operatorname{Re}_{x}^{-1 / 2} N u_{x}$. The variations of $s, \alpha, N r$ and $\xi$ able to defer the flow separations. Two solutions are spotted within the vicinity of the opposing flow $(\lambda<0)$. Stability analysis ratifies the first solution as a stable solution and the second solution as an unstable solution.

\section{ACKNOWLEDGEMENTS}

The first author would like to acknowledge the financial support received from the Ministry of Higher Education (MOHE), Malaysia, in the form of $\mathrm{PhD}$ sponsorship (MyBrain15@ MyPhD), and first two authors would like to acknowledge the research university grant (DIP-2017009) from Universiti Kebangsaan Malaysia. The work of the third author has been supported from the grant PN-IIIP4-ID-PCE-2016-0036, UEFISCDI, Romania.

\section{REFERENCES}

Acrivos, A. 1958. Combined laminar free- and forced-convection heat transfer in external flows. AIChE J. 4(3): 285-289.

Bhatnagar, R.K., Gupta, G. \& Rajagopal, K.R. 1995. Flow of an Oldroyd-B fluid due to a stretching sheet in the presence of a free stream velocity. Int.J. Nonlinear Mech. 30(3): 391-405.

Bhattacharyya, K. \& Layek, G.C. 2011. Effects of suction/ blowing on steady boundary layer stagnation-point flow and heat transfer towards a shrinking sheet with thermal radiation. Int. J. Heat Mass Trans. 54(1-3): 302-307.

Burdujan, I. 2011. The flow of a particular class of Oldroyd-B fluids. Annals of AOSR 3(1): 23-45.
Chen, C.H. 1998. Laminar mixed convection adjacent to vertical, continuously stretching sheets. Heat Mass Transfer 33(5-6): 471-476.

Fetecau, C. \& Fetecau, C. 2003. The first problem of stokes for an Oldroyd-B fluid.Int. J. Nonlinear Mech.38(10): 1539-1544.

Fetecau, C. \& Kannan, K. 2005. A note on an unsteady flow of an Oldroyd-B fluid. Int. J. Math. Math. Sci. 2005(19): 3185-3194.

Guillope, C. \& Saut, J.C. 1990. Global existence and onedimensional nonlinear stability of shearing motions of viscoelastic fluids of Oldroyd type. ESAIM 24(3): 369-401.

Harris, S.D., Ingham, D.B. \& Pop, I. 2009. Mixed convection boundary-layer flow near the stagnation point on a vertical surface in a porous medium: Brinkman model with slip. Transport Porous Med. 77(2): 267-285.

Hayat, T., Kiran, A., Imtiaz, M. \& Alsaedi, A. 2017. Melting heat and thermal radiation effects on stretched flow of an Oldroyd-B fluid. Appl. Math. Mech.- Engl. Ed. 38(7): 957968.

Hayat, T., Muhammad, T., Shehzad, S.A. \& Alsaedi, A. 2015a. Temperature and concentration stratification effects in mixed convection flow of an Oldroyd-B fluid with thermal radiation and chemical reaction. PLOS ONE 10(6): e0127646.

Hayat, T., Waqas, M., Shehzad, S.A. \& Alsaedi, A. 2015b. MHD stagnation point flow of Jeffrey fluid by a radially stretching surface with viscous dissipation and Joule heating. J. Hydrol. Hydromech. 63(4): 311-317.

Hayat, T., Hussain, Z., Farooq, M., Alsaedi, A. \& Obaid, M. 2014. Thermally stratified stagnation point flow of an Oldroyd-B fluid. Int. J. Nonlinear Sci. Numer. Simul. 15(1): 77-86.

Hayat, T., Shehzad, S.A., Alsaedi, A. \& Alhothuali, M.S. 2013. Three-dimensional flow of Oldroyd-B fluid over surface with convective boundary conditions. Appl. Math. Mech.- Engl. Ed. 34(4): 489-500.

Karwe, M.V. \& Jaluria, Y. 1988. Fluid flow and mixed convection transport from a moving plate in rolling and extrusion processes. J. Heat Transfer 110(3): 655-661.

Merkin, J.H. 1985. On dual solutions occurring in mixed convection in a porous medium.J.Eng. Math. 20(2): 171-179.

Miklavčič, M. \& Wang, C.Y. 2006. Viscous flow due to a shrinking sheet. Quart. Appl. Math. 64(2): 283-290.

Oldroyd, J.G. 1958. Non-Newtonian effects in steady motion of some idealized elasto-viscous fluids. Proc. Royal Soc. Lond. A 245(1241): 278-297.

Oldroyd, J.G. 1950. On the formulation of rheological equations of state. Proc. Royal Soc. Lond. A 200(1063): 523-541.

Phan-Tien, N. 1984. Stagnation flows for the Oldroyd-B fluid. Rheol.Acta 23(2): 172-176.

Pop, I. \& Ingham, D.B. 2001. Convective Heat Transfer: Mathematical and Computational Modelling of Viscous Fluids and Porous Media. 1st ed. Oxford: Pergamon.

Rajagopal, K.R. \& Bhatnagar, R.K. 1995. Exact solutions for some simple flows of an Oldroyd-B fluid. Acta Mech.113(14): 233-239.

Roşca, N.C. \& Pop, I. 2013. Mixed convection stagnation point flow past a vertical flat plate with a second order slip: Heat flux case. Int. J. Heat Mass Transf. 65: 102-109.

Sajid, M.,Ahmed, B.\& Abbas, Z. 2015. Steady mixed convection stagnation point flow of MHD Oldroyd-B fluid over a stretching sheet. J. Egyptian Math. Soc. 23(2): 440-444.

Wang, C.Y. 2008. Stagnation flow towards a shrinking sheet. Int J. NonLinear Mech. 43(5): 377-382. 
Waters, N.D. \& King, M.J. 1971. The unsteady flow of an elasticviscous liquid in a straight pipe of circular cross section. $J$. Phys. D: Appl. Phys. 4(2): 204-211.

Weidman, P.D., Kubitschek, D.G. \& Davis, A.M.J. 2006. The effects of transpiration on self-similar boundary layer flow over moving surfaces. Int. J. Eng. Sci. 44(11-12): 730-737.

Kohilavani Naganthran* \& Roslinda Nazar

School of Mathematical Sciences

Faculty of Science and Technology

Universiti Kebangsaan Malaysia

43600 UKM Bangi, Selangor Darul Ehsan

Malaysia
Ioan Pop

Department of Mathematics

Babeş-Bolyai University

R-400084 Cluj-Napoca

Romania

*Corresponding author; email: kohi_kk@yahoo.com

Received: 14 September 2017

Accepted: 12 December 2017 